\title{
CONVERSACIONES CON MUÑOZ MOLINA
}

\author{
José Manuel Begines Hormigo \\ Universidad de Sevilla
}

\begin{abstract}
In the course of this conversation, Antonio Muñoz Molina has boarded different subject connected to Literature and Theory of Literature: the necessity of the tenacious and daily effort, the validity of the occidental canon, the importance of a serious literary tradition, the nature of the imagination, the paper of the book in the contemporary culture, et cetera. In addition to these general aspects, his work and the narrative genre have been treated.
\end{abstract}

Antonio Muñoz Molina (Úbeda, 1956) es uno de los escritores españoles actuales de más relevancia nacional e internacional y, también, una de las mentes más lúcidas de cuantas se preocupan hoy por el arte y por la literatura. De sus méritos dan fe los numerosos reconocimientos a su brillante carrera literaria, tales como el ingreso en la Real Academia Española, el premio Nacional de Literatura, concedido dos veces, y el reciente nombramiento como director de la sede del Instituto Cervantes de Nueva York. Hoy en día, en que la preocupación estética, la disciplina o la responsabilidad artística se consideran valores anticuados y en que se conceptúa el canon culto occidental no como un modelo de lo mejor que el hombre ha hecho a lo largo de la historia, sino como un ente tiránico que señala con el dedo a los que deben y no deben encumbrarse como ejemplo para la literatura posterior, es gratificante y alentador encontrar escritores como Muñoz Molina, que se declara abiertamente imitador -y un sucesor digno, se debería añadir- de los mayores escritores de la historia de la literatura.

Su semblante serio no es incompatible con una cordialidad sincera en sus palabras y con una generosa amabilidad en sus actos. Pese a los numerosos compromisos que lo ocupan constantemente, el novelista andaluz tuvo la gentileza de aceptar un encuentro, a propósito de la publicación de su último libro, Ventanas de Manhattan, y de su recién estrenado cargo como director del Instituto Cervantes de Nueva York. La importancia de este encuentro radica en el hecho de que el escritor ha alcanzado, a sus casi cincuenta años y tras haber publicado numerosas obras, la suficiente madurez intelectual y estética para poder hablar, de una manera general, de su concepción de la literatura.

En Ventanas de Manhattan Muñoz Molina aborda asuntos relacionados con diversas artes: la pintura, la música, la literatura, la fotografía, el cine. El libro es un recorrido poético y detenido por la ciudad, pero contemplada desde los ojos atentos y curiosos de un artista, que se detiene, naturalmente, en las manifestaciones artísticas que encuentra en su caminata. La vida, en esta obra, es disfrutada más intensamente gracias al arte.

En este libro se tratan temas fundamentales de la teoría de la literatura y de la teoría del arte: la diferencia entre la inspiración y la tenacidad diaria del trabajo, la importancia del dominio de la técnica, la materia del arte, el canon, los clásicos, la función del arte, el papel 
del receptor, etcétera. Muñoz Molina empapa sus palabras de un gran sentido común y despoja al arte de cualquier tipo de mitificación o idealismo: "la literatura, el oficio, el gusto de leerla, también es, en el fondo, una cosa algo rancia y bastante artesanal, un trabajo lento y solitario que no interesa a demasiadas personas y en el que siempre tiene que haber un punto de entrega gratuita y azarosa, de devoción íntima"1. El milagro de la poesía, de la experiencia estética, no se produce gracias a la inspiración, sino gracias a una técnica depurada y bien aprendida durante tiempo, que da a la producción artística la apariencia de la naturalidad: "esa maestría [de dos músicos] que borra todo signo de esfuerzo y de premeditación, como si las canciones no estuvieran escritas en pentagramas y fueran interpretadas con el trabajo combinado de los instrumentos y la voz, después de un aprendizaje tenaz de mucho tiempo, de una práctica continua"2.

Ventanas de Manhattan denuncia la cultura actual en la que el libro, la literatura, el arte no son más que objetos de mercado, dependientes de la moda. Contra eso, propone volver al tiempo "de la lentitud necesaria para el disfrute de la literatura y de la vigilancia alerta de la inteligencia", volver a la gran literatura universal, a aquellos libros que han "durado dignamente más allá del tiempo cada vez más fugaz que conceden las normas del mercado y los atolondramientos de la moda" 4 .

En estas páginas, que deben ser entendidas como un diálogo entre un autor y el estudioso de su obra, se insiste en muchas de estas ideas expresadas por escrito en su último libro. Igualmente, se hace referencia a otras muchas novelas del autor y a otros muchos aspectos poéticos y cuestiones artísticas de su obra.

(Esta conversación tuvo lugar una mañana de agosto de dos mil cuatro, en la sede del Instituto Cervantes de Madrid, situada en el número ochenta y dos de la calle Francisco Silvela).

- ¿Qué es para usted la modernidad?

- La modernidad en qué sentido.

- En el sentido literario.

- Lo tengo muy claro en el sentido económico y político pero no sé exactamente qué es en sentido literario. En la tradición anglosajona se llama modernismo al movimiento que empieza un poco con Conrad, con Henry James y, sobre todo, con Joyce, Virginia Woolf y algunos otros; pero la verdad es que no te puedo dar una definición. Hay una modernidad en la pintura y una modernidad en la historia de la literatura. Supongo que es como un salto expresivo, pero no he pensado mucho sobre ese asunto. Se puede decir que sé lo que es como San Agustín el tiempo. También soy consciente de que hay muchos rasgos modernos que parece que estaban antes o que vienen después. De cualquier forma, no es una cosa que a mí me preocupe especialmente.

- Entonces le preocupará todavía menos la postmodernidad en la que supuestamente nos encontramos.

\footnotetext{
${ }^{1}$ A. Muñoz Molina, Ventanas de Manhattan, Barcelona, Seix Barral, 2004, p. 141.

${ }^{2}$ Ibid., p. 51.

${ }^{3}$ Ibid., p. 140.

${ }^{4}$ Ibid., p. 142.
} 
- Es que, verás tú, políticamente y económicamente, el proyecto moderno es el proyecto de la democracia, de la autonomía del individuo, el igualitarismo social y todo eso. Es un proyecto que no está cumplido, que no se ha conseguido: ni la igualdad, ni la justicia, ni la emancipación en el Sahara, ni nada de eso. En ese sentido, yo me siento bastante moderno, porque identifico perfectamente ese proyecto y porque sí he pensado sobre él.

- Se considera entonces moderno.

- Sí, aunque políticamente no vivimos como modernos. Pero me siento moderno, entre otras cosas, porque tengo fe en el progreso científico, porque creo, en fin, en una serie de cosas que es importante conseguir. Cuando muchas veces escucho rasgos de estos que se definen bajo la postmodernidad literaria, me llama mucho la atención que casi todos ellos se pueden encontrar en Cervantes, por ejemplo. Entonces, ¿qué es lo que hay de específico cuando se llevaba tanto hablar de la intertextualidad, o de la autorreferencialidad en la literatura o de...?

- La parodia.

- La parodia. ¿Qué hay de específico en eso? No lo sé, no lo sé. Es evidente que, después de una época en que el paradigma literario o estético dominante, en artes plásticas o en arquitectura, fue el movimiento moderno, vino una época como de mayor relajación expresiva. ¿Se puede considerar eso como posmodernidad? Me parece bien. Es el equivalente en pintura, por ejemplo, al final de la obligación de la abstracción en el arte; y en arquitectura al final de la obligación del racionalismo heredado de la escuela de la bauhaus. En literatura ¿qué es? No lo sé. Tal vez como una especie de mayor libertad a la hora de elegir recursos o temas o cosas así. No lo sé.

- Hay algunos autores que distinguen entre posmodernidad, como un estado cultural, y posmodernismo, como el estilo concreto. Prácticamente no podría hablarse de posmodernismo en literatura. ¿Qué rasgos definirían al posmodernismo?

- Mira, por ejemplo, posmodernismo sería como la no necesidad de asumir la estética vanguardista al límite. Te hablo en términos de mi propia biografía, como lector y como escritor, porque, sinceramente, no tengo necesidad de teorizarlo. A mucha gente de mi generación, un poco mayores, un poco más jóvenes, les ha pasado eso: cuando muchos de nosotros empezamos a escribir o a interesarnos por la literatura en España, había una doctrina ideológica y estética muy fuerte. Ideológicamente implicaba el llamado compromiso inmediato del arte con la realidad y, más que con la realidad, con determinadas posiciones ideológicas. Estéticamente, implicaba como el rechazo de todo aquello que tuviera que ver con lo que se llamaba el realismo o el costumbrismo, previamente parodiado, de manera reductiva, para provocar ese rechazo. Para romper con Galdós, por ejemplo, primero tenías que convertir a Galdós en una parodia de algo que Galdós no era. Ese movimiento de discípulos de Juan Benet, por ejemplo, de cosmopolitismo opuesto a un presunto casticismo de Galdós o de Baroja, implicaba reducir a Galdós y a Baroja a algo que no eran. Galdós y Baroja eran escritores de su tiempo muy modernos, en muchos casos muy experimentales y muy al tanto de lo que se estaba escribiendo y publicando en el mundo. Entonces, para sentirse moderno o postmoderno o lo que fuera, uno tenía que oponer esa supuesta tradición española casposa y garbancera a un internacionalismo literario y cultural que era la leche. Eso en los años 80 era muy inquietante. Muchos de estos movimientos, de estas posiciones, se basan en una simplificación previa de aquello que se quiere atacar o despreciar.

- Es similar a lo que sucede ahora con El Quijote, por ejemplo. Algunos se empeñan en denigrarlo, en hablar mal de él, en referirse a él como una obra que no hay por qué conocer. 
- Tampoco tienen por qué conocer La Ilíada o a Shakespeare o Las Meninas. Peor para ellos. Al Quijote eso no le afecta.

- ¿Qué hace que una obra se convierta en obra maestra?

- Pues yo creo que lo que hace que una obra sea obra maestra es que tenga una capacidad continua de desafiar al lector y de colocar nuevas lecturas. Si lo que define a un clásico, paradójicamente, es su capacidad de no ser clásico.

- El significado siempre es distinto y va cambiando, ¿verdad?

- Claro. También la capacidad de estar siempre como inacabado, como haciéndose, como cambiante. Se supone que lo clásico es lo que está acabado, lo que es perfecto, lo que no puede ser mejorado. Sin embargo, tú comparas, por ejemplo, cómo miraba a Cervantes o al Quijote un lector cultivado de principios del siglo XX y cómo lo vemos ahora, y compruebas que hay una diferencia enorme. El Quijote es el mismo. Entonces, lo que tiene la obra maestra es que ha pasado reiteradamente un examen durísimo, un examen en el que no había enchufe. Por eso cuando están todas estas guerras americanas del canon o del no canon, yo me pregunto: "¿qué canon va a haber en la cultura española?". Todavía la cultura francesa, que es una cultura sólida, hecha. Pero, ¿qué canon va a haber en la cultura española, que es una cultura de un país ignorante, en el que jamás se ha preocupado nadie por los libros, en la que esos autores del llamado canon - esos varones blancos, europeos, muertos- son gente que han vivido en circunstancias marginales? Racine vivía en Versalles, tenía una pensión cojonuda del rey... ¿Pero cómo vivía Cervantes? ¿Cervantes es de un canon opresivo? Si Cervantes es un marginado. ¿Y Quevedo? Quevedo era un tipo personalmente desagradable y que además vivía una vida horrible. Entonces, el canon, el llamado canon, no es una imposición autoritaria, es el resultado de un examen permanente que lleva durando muchos siglos. Eso lleva hasta la supervivencia física de las cosas. ¿Por qué de las tragedias de Sófocles sobreviven esas siete? En parte por azar, pero en parte también porque eran las más copiadas.

- Claro, tiene más probabilidades.

- Hay más probabilidades de sobrevivir. Además, si tienes otros intereses aparte de la literatura, yo creo que eso se puede ver en los contemporáneos. ¿Qué es lo que hace que dure una música, que dure una pintura, o que una pintura desaparezca y reaparezca? Velázquez, por ejemplo, era un pintor bastante secreto hasta que lo descubrió Manet. Manet llegó a Madrid en 1863, me parece, y vio aquello y dijo: "este pintor es contemporáneo mío". Beethoven, que es lo clásico y lo indiscutible, deja escandalizados a aquellas personas que escuchan uno de sus últimos cuartetos. Proust dice una cosa que me parece muy interesante. Proust dice que la obra de arte crea su propia posteridad al ir creando un público converso. Es decir, no hay un público esperando los últimos cuartetos de Beethoven, por la sencilla razón de que son algo inaudito, son algo que no se entiende. ¿Qué público iba a estar esperando En busca del tiempo perdido? Por definición, lo nuevo es inesperado. Entonces, lo que sobrevive, lo que se mantiene, lo hace porque hay gente que a lo largo del tiempo va considerando que tiene un valor y lo va haciendo parte de su vida. Es verdad que también hay que tener en cuenta consideraciones sociales, políticas, y de todo tipo. Que el arte se crea en sociedades de clases, en sociedades mercantiles, en las que los círculos mejores son los que pueden darse a conocer, es indiscutible. A veces no siempre el talento encuentra la mejor manera de abrirse paso: si tú eres pobre y nigeriano tienes muchas menos posibilidades de desarrollar tu talento literario que el señor de clase media y de Zaragoza, pongamos por caso, sin ir más lejos.

- Usted tiene un libro que se llama Las apariencias, que es una selección de artículos. Del libro se deduce que Muñoz Molina trata de desvelar las verdades que esconden las 
apariencias. ¿Cómo se consigue mejor eso: desde la ficción, desde la prensa, desde la narración esta de que ha hablado usted distinguiéndola de la novela?

- En cada caso es distinto. Realmente la obra de arte, la obra literaria, establece un tipo de relación con lo real: por una parte muestra la belleza y por otra muestra su fragilidad, como el arte barroco. Es decir, no se trata de quitar las apariencias y mostrar lo que hay detrás de las apariencias, entre otras cosas porque las apariencias son una parte fundamental de las cosas. Es como esos bodegones barrocos en los que tú ves unas manzanas espléndidas, unos limones, un no sé qué, y, fijándote mucho, ves, allí en una esquina, el puntito negro de la corrupción. Entonces, ese bodegón es varias cosas al mismo tiempo: es un retrato de la maravilla del mundo, de la riqueza de los frutos, y es también un retrato de que eso no va a durar. Entonces, el arte, generalmente, trata de esas cosas tan contradictorias: de la fortaleza y de la fragilidad, del amor y de la traición... Sinceramente, el arte lo que hace es no presentar un solo punto de vista de las cosas. Eso es tarea de la propaganda o de la religión. La religión consiste en que el mundo se reduce a un solo libro. No sé quién dijo que la modernidad cultural europea consiste en que hay muchos libros y muchas lecturas de cualquier libro. Entonces, cuando yo le puse ese título a aquella serie de artículos lo hacía en ese doble sentido. Había pensado ponerle un epígrafe al principio, pero luego se me olvidó, un aforismo a Juan Ramón Jiménez que dice "Las apariencias no engañan".

- Sí lo he leído, no sé si lo cita en algún artículo del libro.

- Yo no sé si lo cito. Ya hace tiempo. A mí me seduce, como creo que a cualquiera, el espectáculo del mundo y lo que está debajo de ese espectáculo. Si te fijas, escritores como Cervantes - este verano he estado leyendo a Cervantes y luego a Henry James- lo que te muestran es que los testimonios sobre las cosas, las impresiones de las cosas son muy chocantes y muy cambiantes. Hay un momento en El Quijote, casi al principio, en la primera parte, cuando se cuenta la historia de Crisóstomo y de la pastora Marcela. Crisóstomo ha muerto porque la pastora Marcela ha sido una malvada y todo eso. Bien. Y de pronto sale Marcela y cuenta su...

- Su propia historia.

- Su propia historia. Entonces, si te fijas, de todo el libro lo que hay es como una incertidumbre. ¡Ojo!, que no es la cosa esta postmoderna de que cualquier opinión sobre las cosas es válida. Quiero decir, simplemente, que hay que poner mucha atención porque hay muchas maneras de ver las cosas y porque hay maneras y maneras. Hay otro momento en el libro, que es prodigioso, en el que, después de que Don Quijote contara, en la venta, unos disparates tremendos de los libros de caballería, se lee la novela de "El curioso impertinente". Yo creo que Cervantes muestra ahí que la literatura puede convertirte en muchas cosas: puede hacerte idiota (vuelve loco a este cretino), o puede mostrar de manera fehaciente y seria cómo pueden ser las reacciones humanas. Tú lees "El curioso impertinente" y parece Henry James. Es una novela de una complejidad deslumbrante. Yo siempre pienso que es una obra maestra invisible porque está escondida dentro de una obra maestra. "El curiosos impertinente" es una novela de una perversidad asombrosa: un tipo que para comprobar el amor de su mujer quiere que su mejor amigo intente acostarse con ella. En El Quijote está continuamente el hecho de que porque una cosa parezca algo no necesariamente lo es. Fíjate que eso está en la base de la conciencia moderna, porque la conciencia moderna no sólo consiste en fijarse en las cosas visibles, sino también en desconfiar, muchas veces, de las cosas visibles. Por ejemplo, para que se acepte la revolución copernicana, hay que rechazar el testimonio de los sentidos, porque los sentidos te dicen que la Tierra está inmóvil y que el sol gira alrededor de la Tierra. Tienes que dar un salto: vamos a desconfiar de esta cosa que parece evidente, de la misma 
manera que vamos a desconfiar del sufrimiento de Crisóstomo, que parece evidente. Mira que si hay otra posibilidad.

- Entonces, se puede decir que la función de la literatura es abrir los ojos o la inteligencia del lector.

- Sí, tiene que ver con eso. Satisface cosas. Eso Cervantes lo hace muy bien también. Satisface pasiones que pueden ser muchas veces muy contradictorias: la necesidad de explicarte el mundo y la necesidad de escaparte del mundo.

- Ahora iba a hablarle sobre eso.

- Claro.

- ¿Qué parte de evasión tiene que haber en la literatura porque, si no la hay, el lector puede aburrirse?

- Claro, claro. A mí me hace mucha gracia Francisco Ayala cuando, al hablar de literatura de evasión, dice: "a mí lo que me evade es Proust". Y es verdad. Es decir, hay una parte de evasión del mundo en la literatura. Es un derecho, el no querer aceptar las cosas como son y el recurrir a la literatura para evadirse. Tu relación con la literatura y con la irrealidad es una cosa muy seria que tú negocias. El pobre don Quijote lo hace hasta un punto insano, igual que la pobre Emma Bovary o igual que los personajes de Palmeras salvajes de Faulkner. No sé si la conoces.

- No

- Esa novela es muy importante por muchas razones, entre otras, porque hay una pareja completamente quijotesca. Son dos presos que se escapan contra su voluntad porque hay una inundación en la cárcel. Hay un preso alto y uno bajito. El preso alto le pregunta al otro: "itú por qué estas preso?"; y dice: "por culpa de los libros". El preso bajo leía novelas de atracos, novelas de gángster, y decidió que tenía que ser atracador. Como don Quijote.

- Sí, usted, en una conferencia que dio sobre El Quijote en Estepa, hablaba precisamente de esto, del peligro que tienen los libros, del peligro de la fícción.

- Claro, claro, eso está siempre. Cervantes tiene eso muy, muy presente. Claro, también es una época en la que los libros están generalizándose más. La imprenta está consiguiendo que la presencia física de los libros sea mucho mayor que antes. Cervantes aborda el tema del peligro de la ficción en esa escena famosa en que se queman los libros. Pero, ¡ojo!, la gente piensa que esa escena es una sátira de lo inquisitorial. Eso no es así. Es un escrutinio muy serio. Vamos a ver qué libros son fértiles para nosotros y cuáles pueden conducirnos a la locura o al mal -qué haríamos nosotros con Mein Kampf, por ejemplo. También te dice no sólo que hay unos libros que son más perjudiciales que otros, sino que hay maneras de leer los libros y que hay que aprender a leerlos.

- Por eso yo le preguntaba. Entonces, ¿para que un libro lo consideremos bueno estéticamente tiene que ser bueno moralmente?

- No, no. La moral de la literatura es distinta de la moral práctica. Es una moral muy ambigua. En la vida práctica, por ejemplo, y en la vida jurídica, tenemos que distinguir perfectamente entre un verdugo y una víctima. Eso es fundamental. Pero la literatura con frecuencia puede ponerse en el lugar del verdugo: Tom Ripley, por ejemplo, de Patricia Highsmith. Ripley es un asesino y es el héroe de esas novelas. Entonces, el sistema moral del arte es distinto del sistema moral de la vida común. Una de las cuestiones quizás más importantes del saber leer consiste, precisamente, en esa distancia. 
- Hay que juzgar con otros criterios la literatura.

- Claro, claro, claro.

- Se ha hablado de la responsabilidad del artista, de la responsabilidad moral, estética... ¿De qué manera se refleja eso en una novela o en un artículo de prensa, donde creo que es más fácil verter una ideología o una moral?

- Es muy distinto. Muy distinto por esa razón que te decía antes. La novela es en gran parte inconsciente. Tú decides escribir un artículo y decides las ideas que van a ir en ese artículo, del que, hasta cierto punto, controlas el sentido ideológico o moral que tiene. Ahora, en una novela, si es buena, tú solo controlas hasta cierto punto, porque trabajas con materiales inconscientes, porque trabajas con materiales muy ambiguos y porque trabajas con un retrato de la vida que por definición, si la novela es buena, tiene que ser muy poliédrico. La responsabilidad, por tanto, es distinta. La responsabilidad del novelista es hacer la mejor novela que pueda. Y esa responsabilidad del novelista se corresponde con la responsabilidad del lector, también de lo que decíamos antes. La responsabilidad del que escribe artículos, en cambio, es una responsabilidad civil o ciudadana, es decir, qué efectos puede tener aquello que yo estoy escribiendo. Decía Wilbert-Collins, en un artículo del año 37, decía cómo puedo escribir yo un artículo animando a un joven a morir en la guerra de España. Yo no voy a ir a la guerra de España, pero puedo hacer que alguien vaya y que muera. Eso es muy inquietante.

- Usted ha escrito cuentos, novela, novela corta, cuentos que se han convertido luego en novela corta. ¿Podría decirme algunas características que considera propias de cada uno de esos tres géneros?

- Mira, el cuento tiene una unidad de lectura y tiene más que ver casi con el poema, en el sentido de que es un impacto. Conforme se va haciendo más largo, se va convirtiendo en otra cosa, que a mí me seduce muchísimo, se va convirtiendo en algo que tiene, por una parte, la austeridad y las exigencias formales del cuento y, por otra parte, la libertad de vuelo de la novela. Por eso hay tantas obras maestras que son novelas cortas. Hay una devoción inmensa por ese género tan raro que tiene lo mejor de dos mundos. ¿Por qué? El cuento puede tender al abuso de su forma, es decir, todas las formas llevan dentro el peligro...

- De su parodia.

- De su propia parodia ¿no? Entonces, claro, cuando estás trabajando con una forma, estás negociando con una resistencia de materiales. El cuento puede ser perfecto, pero demasiada perfección lo convierte en una baratija, como en un bijou. La novela tiene la ventaja de la libertad. Las grandes novelas son un poco ambulantes. Por definición, la novela tiende a lo proteico, a lo abundante, y, claro, también puede desparramarse. El compromiso -como con la piedra filosofal ahí- sería una buena novela corta en la que existe la posibilidad de juntarlo todo. Cuando yo era joven, me gustaban mucho las novelas de Julio Verne. Siempre me preguntaba por qué no fue Baudelaire el que escribió Viaje al centro de la tierra. Habría sido perfecto: una trama maravillosa y un escritor magnífico. Porque el pobre Verne es un escritor de garrafa. Entonces, yo creo que la novela corta es ese sueño de juntar lo mejor.

- Ya que ha hablado de su juventud. Una de las primeras cosas que escribió fue este inicio de poema sobre la conquista de la luna o algo así.

- "La Selenea"

- "La Selenea", eso es. ¿Ha tratado de acercarse nuevamente a la poesía o al teatro de alguna manera? 
- A mí el teatro me gustaba mucho, pero lo dejé por razones prácticas. Fue una decisión fría de la que me alegro. La poesía es que es una cosa que viene dada. La poesía a mí me parece una cosa muy seria. Creo que la poesía es el efecto máximo al que aspira una obra de arte. El grado máximo de expresión o de misterio de una obra de arte es poesía. La poesía de una película o de un momento de una novela, por ejemplo. Luego está la poesía en cuanto a forma literaria, que se confunde a veces con el verso y que para mí es el grado máximo de la expresión. Yo de vez en cuando escribía algún poema, pero después, no sé, ya no se me ocurrieron ninguno. Fui abandonándolo, pero no creo que el mundo perdiera nada.

- Es que creo recordar haber leído en algún sitio que había intentado escribir teatro o que incluso había escrito alguna obra.

- Cuando tenía diecisiete o dieciocho años.

- ¿Pero es desconocido?

- Estrené, estrené. Una adaptación que hice de El principito que se representó mucho por Andalucía. Hice bastantes cosas, pero me di cuenta de que era difícil hacer teatro en la época en que estaba, en los setenta. Era una época en que el autor estaba mal visto en el teatro. Todo era creación colectiva. Me acuerdo que la compañía que hizo esta versión que yo había hecho de El principito puso en el cartel "creación colectiva". Entonces, indignado, fui yo al tío y le dije: "oye, qué creación colectiva ni creación colectiva. Lo que estáis diciendo aquí, de la primera a la última palabra, es o bien de Antoine Saint-Exupery o bien mío. Qué leche creación colectiva". Entonces me lo planteé fríamente: si yo escribo una obra de teatro, lo que se va a ver, el resultado final, sólo va a ser una parte pequeña de lo que yo he hecho; si yo escribo un cuento, es mío cien por cien, en lo bueno y en lo malo. Lo pensé, lo pensé fríamente. Me gustaba mucho, mucho. Además me puse a leer a Borges, El jardín de senderos que se bifurcan y comencé a olvidarme del teatro.

- Se metió Borges por medio. En cuanto a otros géneros, ¿Córdoba de los Omeyas es un ensayo? También hay algunos capítulos que pueden leerse como verdaderos cuentecillos.

- Sí, ¿sabes lo que ocurre? Yo creo que hay que distinguir, y en España se confunde, lo que es ficción de lo que es narración. Se pueden hacer espléndidas narraciones, y muchos historiadores británicos, sobre todo, lo han hecho, que no son ficción. Una de mis lecturas preferidas es La historia de la decadencia y caida del imperio romano de Gibbon. Gibbon es un narrador como los de los grandes ciclos narrativos. Es un narrador perfecto, como el narrador de En busca del tiempo perdido, pero sin hacer ficción. Trevor-Roper, el autor del libro Los últimos días de Hitler, hace un libro buenísimo que no tiene nada de ficción. Muchos en la literatura americana y anglosajona lo hacen. Yo intenté hacer eso más cuidadosamente después, en Ardor guerrero. Intenté utilizar todos los recursos de la narración para contar cosas que no son ficción. Entonces, el libro ese de Córdoba fue un ensayo para una colección que había, y a lo que tuve que hacer frente sobre la marcha. En la introducción, por ejemplo, fue la primera vez que yo escribí algo narrativo sin fícción y en primera persona. Yo lo iba escribiendo y no sabía lo que era, pero tenía como una cierta necesidad estética de poner eso al principio de ese libro. Córdoba de los Omeyas es el relato del paseo por la ciudad, que se parece mucho a lo que hice en mi libro de Manhattan, y, por otra parte, era también el intento de dar forma narrativa a un material que era histórico. Era un ejercicio que a mí me vino muy bien, porque me hizo salir un poco de mi mundo y me forzó a escribir de otra manera, a soltar la mano.

- Ahora que menciona Ardor guerrero, ¿nada de lo que se cuenta en el libro es ficción?

- En absoluto. 
- El lector puede sentir cierta inseguridad y pensar, tal vez, que no debe dejarse engañar por el narrador.

- No, eso es un acuerdo que lo hacen mucho los anglosajones. En los países latinos la idea del acuerdo veraz no es muy frecuente, porque nos gusta mucho engañarnos unos a otros. Pero en el mundo anglosajón existe esa cosa del acuerdo, del pacto personal. Yo creo que en la literatura tú estableces un pacto con el lector. Y eso lo pongo al principio del libro: esto es un libro honrado, trata sólo de mí. Entonces yo, lo que hice, fue contar narrativamente mis recuerdos. En parte, la forma de este libro está inspirada en una literatura americana riquísima, de no-fícción, que empecé a descubrir cuando estuve dando clases en la universidad de Virginia, que fue el momento en que comencé a escribir el libro. Yo podía haber hecho una novela con esto, pero no quise. Ardor guerrero causó mucho mal entendido, porque decían esa cosa malévola: "como no se le ocurren novelas o tal". Vamos a ver ¿me acusa de no haber hecho una novela y al mismo tiempo dice que es una novela? Pero no escribí una novela, escribí un libro que no es ficción.

- El dueño del secreto y El jinete polaco sí son novelas.

- Evidentemente.

- Y ahí se supone que también hay rasgos autobiográficos.

- Son ficciones autobiográficas, claro, pero la relación con lo real es completamente distinta. En esa, y en muchas otras cosas que yo he escrito, los materiales muchas veces son autobiográficos. Hay que tener mucho cuidado en saber distinguir en qué consiste lo autobiográfico. Un ejemplo: un personaje que hay en El jinete polaco que, en apariencia y por razones evidentes, no tiene nada que ver conmigo biográficamente, es el comandante Galaz. Sin embargo, hay partes que son muy autobiográficas porque están alimentadas por sensaciones o por cosas mías. Lo que ocurre es que lo autobiográfico, en la ficción, es un material, igual que un escultor puede trabajar con el bronce o con el mármol o con la piedra. Entonces, tú trabajas con ciertos materiales: una parte de esos materiales son literalmente autobiográficos, otra parte son autobiográficos, pero en un sentido más ambiguo, y otra parte son perfectamente inventados. La amalgama es la ficción, basta una gota de ficción para que el material autobiográfico cambie por completo. ¿Por qué? Hay una diferencia que está muy clara: cuando escribes una autobiografía escribes la vida que has tenido; cuando escribes ficción generalmente utilizas vidas que podías haber tenido. Es decir, la vida del protagonista de El dueño del secreto, por ejemplo, se parece a la mía, podía haber sido la mía, pero hay cosas que no son, afortunadamente para mí: yo no trabajo en una gestoría. Ese personaje es autobiográfico en el sentido en que un miedo, un terror enorme de mi vida en esa época, era acabar trabajando en una gestoría de mi pueblo. Claro, entonces es autobiográfico. Yo siempre pongo el ejemplo de lo autobiográfico en Stendhal, con Fabrizio del Dongo y Julien Sorel. Los dos son autobiográficos, aunque de manera distinta, y ninguno es autobiográfico porque literalmente ninguno es Stendhal.

- Entonces, la materia de su obra está basada en su propia vida. Usted habla, en distintos escritos, de la memoria y de la imaginación a partir de esa memoria. ¿Qué es más importante para usted?

- La ficción consiste en la mezcla. Eso que decía de la gota, como la química: tienes un vaso con un líquido que es blanco, echas una gota y no pasa nada, echas otra gota y no pasa nada, echas la tercera gota y, por arte de magia, se convierte en otra cosa. Eso es así. Muchas veces, tú lees novelas en las que lo autobiográfico no ha madurado lo suficiente en ficción y entonces son autobiografías disfrazadas. Esas novelas tan frecuentes de los periodistas en las 
que, en vez de ser un periodista que está en Beirut, es un hombre de negocios que está en Beirut y al que le pasa lo mismo que le ha pasado al periodista. O esas novelas que son proyecciones adolescentes de cómo el autor se ve a sí mismo.

- Eso formaría parte de la imaginación.

- Claro. Si te fijas, muchas novelas de esas son muy pueriles porque ves que el autor tiene una idea de sí mismo acojonante, una idea que la pone en práctica en la novela.

- Usted parodia eso con algunos personajes. Manuel de El jinete polaco está siempre imaginando lo que podía ser, lo que podía haber sido, las vidas que podía haber vivido.

- Claro, claro. Hay un libro que ha hecho un señor de Valencia, Justo Serna, que se llama Pasados ejemplares. Es un libro bastante bueno sobre mi trabajo en el que se centra, sobre todo, en ese aspecto, en el aspecto de las vidas posibles.

- La oralidad también es muy importante en su obra, por lo menos en El jinete polaco o en Beatus ille, donde existen personajes que se cuentan historias unos a otros. Incluso en Ventanas de Manhattan cuentan las historias del metro, de gente que empuja a otras justo cuando va a llegar el metro. De todas maneras parece que en Ventanas de Manhattan no está tan presente esa oralidad, sino que aparece sólo en determinados momentos.

- Claro, porque el centro de ese libro implica casi el silencio. Es un libro concebido sobre todo, aunque hay muchas historias y hay gente que cuentan historias y conversaciones, desde una mirada solitaria, desde la mirada de un caminante solitario. Siento predilección, a pesar de todo, por los momentos del libro en que alguien cuenta algo. La gente que cuenta cosas está muy presente en mis libros. Carlota Fainberg, por ejemplo.

- Es una conversación.

- Es una conversación.

- Y la historia que más interesa, por cierto, es la de Abengoa, no la de Claudio.

- Es que Abengoa está bien, ¿no?

- ¿Qué me dice de Mágina? ¿Es un espacio mítico que deja de serlo a lo largo de su trayectoria o nunca fue un espacio mítico?

- Eso de espacio mítico son palabras demasiado elevadas. Yo me acuerdo de un novelista que decía: "no sé si crear un territorio mítico". Qué bien, qué suerte tener esa potestad. Es un espacio poético: poético en el sentido de que es un recurso literario. Un recurso literario en el que cristaliza una zona de eso que hablábamos antes: de experiencia y de imaginación. Es decir, si yo cuento algo que pasa en Úbeda, estoy contando algo que pertenece a un mundo que comparten otros. Si yo cuento que pasa en Mágina, esa gota, se convierte en otra cosa porque Mágina no existe. Entonces, es un artificio que a mí me ha venido muy bien en muchos sentidos. Cuando lo he usado explícitamente y cuando lo he usado implícitamente.

- Cuando aparece como trasfondo.

- Claro. Para mí fue muy importante, por ejemplo, cuando se me ocurrió que la acción de Plenilunio iba a suceder en Mágina y no en Granada, donde había sucedido el crimen en el que yo me inspiraba. Al sacar de un espacio literal unos hechos, esos hechos están más cerca de la fícción, es más fácil transmutarlo en ficción. Mágina también es un sitio de encuentro. Es una cosa que para mí ha sido siempre muy importante: esos escritores que crean mundos que están por encima de los libros, interreferenciales. Balzac, Proust, Faulkner, evidentemente Onetti... Esa interreferencialidad le da al lector como una sensación de... 


\section{- Familiaridad}

- De familiaridad. Tú no tienes que explicarlo todo. Eso crea con el lector -la palabra complicidad está muy devaluada- una especie de confabulación. Si yo abro una página de Proust al azar, leo cinco líneas y reconozco todo, incluso sé cosas que él no tiene que decirme. Eso pasa en música en Wagner, por ejemplo, con el leitmotiv que se repite. Ese paso narrativo, de dimensión tan grande, me da un placer muy íntimo y un placer absolutamente innecesario y gratuito: el hecho de establecer pequeñas conexiones.

- También crea esa complicidad el recurso este de hacer que el personaje secundario aparezca en distintas novelas, como Luque que aparecía en Beatus ille o en El jinete polaco.

- Claro, claro, en Beltenebros también sale. Entonces eso les da a los personajes como un mayor relieve, los hace como...

- Más reales.

- Más reales. Además hay que procurar, por lo menos yo procuro, que no sea evidente. Por ejemplo, en un momento de Plenilunio, donde yo tenía que inventarme la escena en que el inspector y la maestra cenan juntos, se me presentó el siguiente problema: imaginándome los alrededores de mi pueblo, no podía imaginar un sitio estupendo al que ir a cenar, era todo muy bárbaro, unos bares atroces con unas raciones de orejas en salsa que... Entonces, de pronto, imaginé un restaurante bonito, cercano al río y tal, y de pronto se me ocurrió: imagínate que aquel cortijo de Beatus ille con el tiempo se ha convertido en un restaurante. Porque, ¿cuál es la historia de los sitios? Esta casa, por ejemplo, que se llama Villa Trinidad, se la hizo un millonario de Madrid, a principio del siglo XX, a su amante, que se llamaba Trini. Pero es que después fue cuartel de la Gestapo. ¿Qué sabemos de los sitios? Eso Onetti lo hace mucho. Mis mayores maestros en muchos sentidos -Onetti, Proust, Wagner, Faulkner- lo hacen mucho.

- ¿Cuál es el gran personaje que ha creado? ¿Lorencito Quesada?

- Hombre, Lorencito Quesada está bien.

- Yo creo que es el personaje suyo que más me gusta.

- Está bien, yo le tengo cariño. Tuvo mala suerte, cuando hice la novela aquella. Me acuerdo de un crítico que me encontré en el aeropuerto y dice: "¡Mañana me cargo tu novela!, -con un hedor que le echaba la boca a coñac- ¡mañana me cargo tu novela!”. Pobrecito, ¿no? Muchas veces me gustaría, no sé, hacer otra aventura suya. Claro, ya tendría que trabajar en la televisión local o algo. Es muy cervantino, ¿verdad?, el pobre. Figúrate, dicen: "le puso usted Quesada por lo de Quesada o Quijana". No, es por el sonido. Pero bueno, a mí me gusta. Y cuando en otro cuento que sale, no me acuerdo cómo se llama.

- Sí, en "El cuarto del fantasma".

- "El cuarto del fantasma". Ahí está muy bien, cuando habla de la redención, de los extraterrestres y todo eso. Y en El jinete polaco cuando habla del soneto misterioso, del romance anónimo. A él siempre le gustan estas cosas de las pirámides, de los extraterrestres y de todo eso. ¿Sabes que luego hay dos tipos que se agobian porque los dos están convencidos de que son el modelo?

- Sí, se lo iba a comentar ahora, hay gente que se entretiene en buscarle modelo al periodista. De todas maneras, yo, que también vivo en un pueblo, encuentro a este Lorencito Quesada en la realidad. 
- Claro que sí.

- Supongo que habrá uno en cada pueblo.

- Eso pasa como en Carlota Fainberg, cuando la gente me dice: "esta Mariategui es tal tía del departamento de tal". Digo no, es que hay muchas así. Entonces, en Úbeda hay uno que se llama, creo, Quesada, Quesada Consuegra.

\section{- Sí, Quesada Consuegra.}

- Que trabajó, yo eso no lo sabía, en el Métrico. Eso del Sistema Métrico lo deduje yo: estos nombres lo pondrían cuando el sistema métrico decimal era una innovación estupenda, que iba a acabar con todas esas cosas arcaicas de los codos, los palmos. Frente a eso, el metro. Era una cosa como de afirmación progresista. Luego hay otro también que tiene cierto parecido con Lorencito. Una vez, uno de ellos me hizo una entrevista para la televisión local de Úbeda y, al final de la entrevista, me dice: "Antonio, -dice- en Úbeda hay una polémica y tal, a ver si tú nos puedes aclarar algo". Se me queda mirando y dice: "¿Quién es Lorencito Quesada?". Entonces, Dios me iluminó y digo, "te lo voy a decir: Lorencito Quesada soy yo. Lorencito Quesada es mi miedo al mundo y al fracaso". A mí me gusta más todavía el admirador de Lorencito Quesada.

- El farmacéutico que transcribe su aventura.

- Claro, claro, que para él, Lorencito Quesada es como Dios.

- Pero es que además este Quesada Consuegra tiene un estilo muy parecido al de Lorencito.

$$
\text { - ¿Sí? }
$$

- Sí, es verdad. Siguiendo con los personajes, suele utilizar personajes fracasados o víctimas. ¿Es por eso que ha dicho alguna vez de que el escritor tiene que dar voz a los que no la tienen?

- No, no es por una cuestión moral. Ocurre que en la literatura, con mucha frecuencia, la novela, que es un género bastardo, se ha ocupado de gente que no tenía quien la cantara. ¿Por qué el Lazarillo escribe su historia en primera persona? Porque si él no la cuenta, no la va a contar nadie. Entonces hay algo en la novela que lleva a eso. Pero, en mi caso, yo creo que en el de nadie, no hay una decisión moral ni nada de eso. Simplemente, se escribe sobre ese tipo de personajes que se parecen bastante entre sí, que suelen ser eso: desvalidos, sentimentales.

- Le he hecho esta pregunta porque usted cuenta, en alguna ocasión, que un escritor le había pedido materiales sobre dictadores, o algo así, para darle la voz a los dictadores, para ver qué se cuece en el interior de esas personas.

- Ah sí, me pidió si yo tenía documentación sobre los jefes nazis, de campos de concentración nazi. Yo le dije que a mí eso no me interesaba.

- Decía usted que lo que interesaba era la voz de la víctima.

- Pero eso ya es una cuestión no literaria sino hasta política.

- La naturalidad, la ironía, el humor y el sentido común son los ingredientes básicos para ser un buen escritor.

- No, no necesariamente. Yo creo que toda persona que hace algo muy bien tiende a ser natural, porque ha dominado muy profundamente una técnica o una serie de recursos. La 
naturalidad es la consecuencia de un adiestramiento muy, muy persistente, pero no sólo en la literatura, en todo. Se empieza por la rigidez y se sigue por la naturalidad, si hay suerte. En música, en todo, hasta para producir coches. Entonces eso, la naturalidad, la ironía, el sentido común son rasgos que se encuentran muchas veces en la gran literatura. ¿Por qué? Pues quizás porque la gran literatura trata de una visión cordial del mundo, de una visión equilibrada, de una visión hasta cierto punto evangélica (evangélica en el sentido de que la literatura parte del hecho de que cualquier día merece ser contado, y que cualquier experiencia puede ser tan importante como cualquier otra). Eso, claro, implica el reconocimiento de que toda vida es fundamental.

- Y que es más importante la vida que la literatura

- Evidentemente. Para mí la literatura no es lo más importante.

- ¿Cómo le gusta que se acerque el lector a su obra?

- No sé, con curiosidad y con afecto, si puede ser.

- ¿Y el crítico literario o el teórico literario que también son, al fin y al cabo, lectores?

- Son lectores, pero más cualificados. A mí me gusta mucho hacer crítica literaria. No sólo literaria, a veces he hecho crítica de arte o de música o de cosas así. Para lo que sirve la crítica es como un instrumento de aproximación a la obra. Es decir, la buena crítica de un cuadro es aquella que te ayuda a mirar mejor un cuadro. Por ejemplo, la manera en que Panofski te explica los cuadros del Renacimiento hace que mires mejor. Pues para mí la crítica es eso.

- ¿Cuál es el principal problema con el que se encuentra al empezar una novela, si lo hay?

- Todo. El principio y el tono.

- En relación con la función que va a desempeñar en Estados Unidos como director: ¿Cree que eso lo va a acercar más a la literatura estadounidense o va a tener más relación con ella? ¿Le interesa la literatura estadounidense?

- Sí mucho. Es que a mí me gusta mucho, mucho la lengua inglesa, y la lengua es una cosa que forma parte de la literatura. Gracias a ese gusto por la lengua he aprendido mucho de la literatura en inglés, no sólo de la americana. Así que el hecho de estar sumergido en el idioma me produce mucho placer, mucha felicidad.

- ¿Se siente maestro de las nuevas generaciones?

- No, en absoluto.

- ¿No se encuentra imitado en los libros contemporáneos?

- Tampoco me fijo mucho en eso. Pero yo creo que, generalmente, uno busca sus maestros a una cierta distancia. Es raro que un buen maestro tuyo sea alguien que está separado de ti por un espacio corto de tiempo. Un maestro tiene que ser muy distinto de ti. Entonces, tener influencias de un contemporáneo es difícil, porque, en realidad, nos parecemos mucho.

- ¿Lee algún escritor contemporáneo español? ¿Le gusta algún escritor en especial?

- Por supuesto, claro. Leo a muchos.

- ¿Puede decir algún nombre?

- No, para qué. 
- ¿Cómo le gustaría ser recordado, que recordaran su obra?

- A mí no me gusta pensar en esas cosas.

- Pues nada más, muchas gracias por atenderme.

De las palabras de Antonio Muñoz Molina queda siempre, sobre todo, una sensación intensa de honestidad y de humildad, la certeza de estar ante un hombre que ama, con pasión, todos los ámbitos de la palabra y la conciencia clara de asistir al triunfo del sentido común.

En esta conversación, el escritor ubetense ha tratado, con una gran inteligencia, temas muy complejos, relacionados con la teoría literaria y con su propia concepción del arte: la existencia de un canon de la literatura occidental y de la literatura española, la existencia discutible o la inexistencia de la postmodernidad como un estilo literario concreto, la diferencia entre los distintos subgéneros narrativos y entre los distintos géneros literarios, la función de la literatura como aguzadora de la lucidez del lector, la importancia de los materiales autobiográficos en su imaginario poético, etcétera.

Una de las aportaciones más interesantes del autor es el establecimiento de un género muy utilizado en la tradición anglosajona y poco usado, según él, en la española: la narración no ficticia. Ardor guerrero o Córdoba de los Omeyas pertenecerían a este subgénero narrativo. Cuando el lector se enfrenta a este tipo de narraciones y las interpreta como ficticias, corre un riesgo similar al de interpretar como reales las narraciones que son ficticias. En este sentido, se habla, en varios momentos, en relación con El Quijote, del peligro de los libros y del peligro de los malos lectores, o de los lectores entusiastas, que no son capaces de discernir la realidad y la ficción. Las continuas referencias a Cervantes y a su obra maestra dejan clara su devoción y admiración por El Quijote, del que se declara apasionado.

Para terminar, en las palabras, y también en las obras, de Muñoz Molina, que es un gran escritor, pueden encontrarse las características que definen a la gran literatura, porque, como él mismo dice a lo largo de la conversación, "la naturalidad, la ironía, el sentido común son rasgos que se encuentran muchas veces en la gran literatura [...] porque la gran literatura trata de una visión cordial del mundo". 